\title{
A PROSPECTIVE STUDY OF THE INCIDENCE OF CONVERSION OF LAPAROSCOPIC CHOLECYSTECTOMY TO OPEN CHOLECYSTECTOMY IN 100 PATIENTS
}

\author{
**Halim El Thany Nader Halim Grace, *Refaat Refaat Kamel,* Hany Rafik, \\ *Mohammed Abd El-Sattar
}

Department of General Surgery, Faculty of Medicine, Ain Shams University, and ** Department of General Surgery Anglo. American Hospital, Egypt.

Corresponding author Halim El Thany N. Halim Grace Mobile: 01013308266

E.mail:

halimnadergrace84@outlook.com

Received: $18 / 3 / 2021$

Accepted: 14/4/2021

Online ISSN: 2735-3540

\section{ABSTRACT:}

Background: Laparoscopic cholecystectomy is the gold standard treatment for symptomatic gallstones. Conversion to an open procedure is necessary in 5-10\% of patients.

The aim of work: The present study was to illustrate the incidence of conversion of laparoscopic cholecystectomy to open cholecystectomy \& to validate the efficacy of "CLOC" (Conversion from Laparoscopic to open cholecystectomy) risk scoring system on the patients included in the study.

Patients and methods: The present observational prospective study was conducted in EL-Demerdash Teaching Hospital (January 2019- January 2020). The study included (100) symptomatic cholelithiasis patients. Patients were divided into two groups, firstly those who completed laparoscopic cholecystectomy and secondly those who were converted into open cholecystectomy. Preoperative variables included patient demographics, indications for surgery, ASA grade, admission type, ultrasound findings and preoperative endoscopic retrograde cholangiopancreatography (ERCP). Validation of the "CLOC" scoring system was applied to all patients. Operative data were gathered prospectively, and the difficulty of the procedure was graded using the Nassar scale (grades 1-4).

Results: (24\%) of patients recorded difficult total score; open surgery was conducted in (5\%). There was statistically significant relation between CLOC risk scoring level and age $(p<0.001)$; indication ( $p=0.002) ; A S A(p=0.002) ;$ gallbladder wall thickness. $(p<0.001)$ and preoperative ERCP patients $(p=0.003)$. There was statistically significant increase in difficulty in male compared to female. $(p=0.019)$. There was actual conversion according to groups with 'high risk scoring $>7$ and conversions in the' low risk $>6$ easy' group below. $(p=0.042)$; highly statistically significant increase of mean in difficult group compared to essay group $(p<0.001)$. The difficult group complications rate was higher than the easy group (75\% versus $10.5 \%)$; gallbladder rupture was mostly reported in (37.5\% and 2.6\%) of difficult group and easy group cases, respectively. Receiver operating characteristics (ROC) curve sensitivity was 92\%; specificity was 98.7\%. Age, gender, indication, ASA, gallbladder wall and Pre-Operative ERCP have a significant effect on the difficulty.

Conclusion: The present study could conclude that parameters as older age, male gender, cholecystitis, ASA, thick wall GB, preoperative ERCP are predictors for difficult LC. Meanwhile these 
Halim El Thany Nader Halim Grace, et al.,

factors are predictors for conversion to open cholecystectomy. CLOC" risk score may be the most helpful tool in stratifying risks.

Keywords: Laparoscopic, cholecystectomy, Conversion, CLOC" risk score

\section{INTRODUCTION:}

Laparoscopic cholecystectomy is the gold standard treatment for symptomatic gallstones. Conversion to an open procedure is necessary in $5-10 \%$ of patients, and is associated with increased morbidity, prolonged hospitalization and longer recovery in comparison to a laparoscopic approach $^{1}$.

Several factors increase the conversion risk to open, including age, male sex, obesity, cholecystitis and previous Endoscopic retrograde cholangiopancreatography ${ }^{2}$. Some experts had been trying to gather predicting factors and incorporate them in form of a scoring model (such as CLOC Conversion from Laparoscopic to open cholecystectomy) score. Risk score for conversion from laparoscopic to open cholecystectomy" (RSCLO) score and the prediction nomogram ${ }^{3}$.

Conversion is also associated with complications including death, bile duct injury, bile leak, or bleeding, needing reoperation or transfusion. Identifying risk factors for conversion allowed safer procedures and better surgical planning. A systematic assessment of these factors preoperatively allows determination of whether open surgery should be performed initially, avoiding the potential complications brought through an intraoperative conversion from Laparoscopic cholecystectomy to open cholecystectomy ${ }^{4}$.

\section{AIM OF THE WORK:}

The aim of the current study was to demonstrate the incidence of conversion of laparoscopic cholecystectomy to open cholecystectomy \& to validate the efficacy of "CLOC" risk scoring system on the patients.

\section{PATIENTS AND METHODS}

The study was conducted from January 2019 to January 2020 in EL-Demerdash Teaching Hospital. A total of 100 patients with symptomatic cholelithiasis were included; patients were divided into two groups, firstly those subjected to laparoscopic cholecystectomy and secondly those who were converted from laparoscopic to open cholecystectomy. Patients were excluded if they had palpable tender lump in right hypochondrium; portal hypertension; peritonitis; deranged liver function tests; coagulopathy and pregnancy. The study was approved by the medical and Ethical Committee of Ain shams University, Faculty of Medicine and all the patients were informed about the study and a written consent was obtained from all.

The admission sheet was utilized to collect data about: the patients ${ }^{\text {ee }}$ characteristics (Gender, Age, Weight and height for Body mass index calculation). Detailed Clinical examination of the patient was done. Ultrasonography was performed for all patients following standardized protocol with assessment of gallbladder size and shape, Pericholycystic collection, gallbladder wall thickness, the size and number of calculi, and preoperative endoscopic retrograde cholangiopancreatography (ERCP).

Prophylactic antibiotics were given intravenously in a single preoperative dose within one hour of skin incision and redosed when the procedure is more than 4 hours long, NPO for at least 6 hours, 
abdomen and groin area shower and cleaning with mild antibacterial soap, Deep Venous Thrombosis Prophylaxis in patients with two or more risk factors. Surgical procedure of LC was performed on the standard 4-ports technique, Post operatively the nasogastric tube was removed at the end of operation, the drain, if inserted, was removed in the following day if there is no bile in it and minimal blood loss has occurred and Majority of patients were discharged on the following day.

Validation of the "CLOC" scoring system was applied to all patients. A CLOC score equal or more than 6 was considered a high risk patient for conversion. A CLOC score below 6 was considered a low risk patient for conversion ${ }^{2}$.

Operative data were also gathered prospectively, and the difficulty of the procedure was graded using the Nassar scale (grades 1-4).

\section{Statistical analysis:}

Recorded data were analyzed using the statistical package for social sciences, version 20.0 (SPSS Inc., Chicago, Illinois, USA). Quantitative data were expressed as mean \pm standard deviation (SD). Qualitative data were expressed as frequency and percentage.

- Chi-square (x2) test of significance was used in order to compare proportions between qualitative parameters.

- Binary logistic regression: was used to predict the outcome of categorical variable based on one or more predictor variables.

- The confidence interval was set to $95 \%$ and the margin of error accepted was set to $5 \%$. So, the p-value was considered significant as the following:

- Probability (P-value):

- P-value $<0.05$ was considered significant.

- P-value $<0.001$ was considered as highly significant.

- P-value $>0.05$ was considered insignificant.

\section{RESULTS}

In the current study; (29\%) of the study group were $<30$ years; (36\%) were 30-39 years; $(29 \%)$ were $40-69$ years and $(6 \%)$ were over 70 years old. Diagram (1): $(60 \%)$ of the study group were females while male represented $(40 \%)$. Cholecystitis was the most reported indication $(76 \%)$; while the colic/pancreatitis represented (24\%) of indications.

Table (1) showed that (68\%) of the study group recorded ASA I, (32\%) ASA II and $(0 \%)$ ASA III+. Diagram (2) shows that $(61 \%)$ of the study cases had normal gallbladder wall; while (39\%) had thick wall.

Table (2) showed that (95\%) of the study cases had normal CBD diameter while preoperative ERCP was done in $(5 \%)$.

According to CLOC risk scoring system $(76 \%)$ of the study cases recorded easy total score; while $(24 \%)$ recorded difficult total score. Laparoscopic cholecystectomy (LC) was conducted in $(95 \%)$ of the study cases; while open surgery was conducted in $(5 \%)$ of the study cases. 


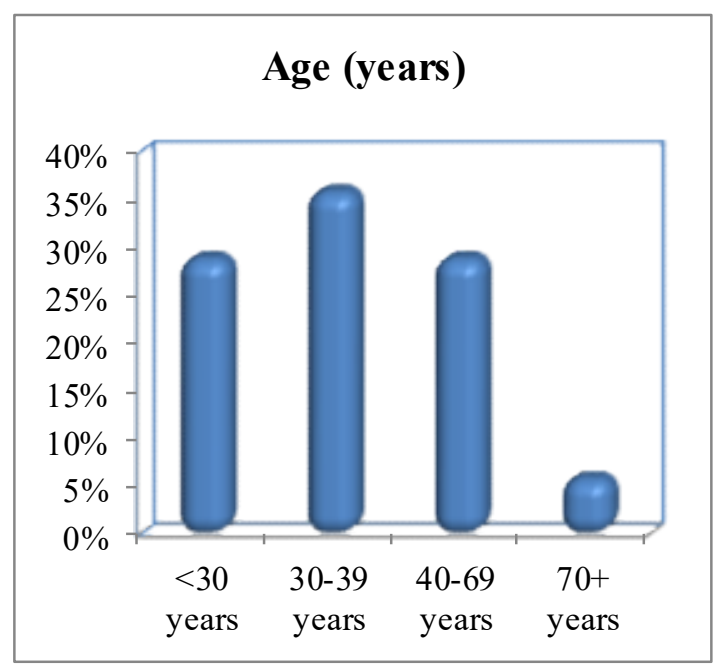

Diagram (1): Age (years) distribution

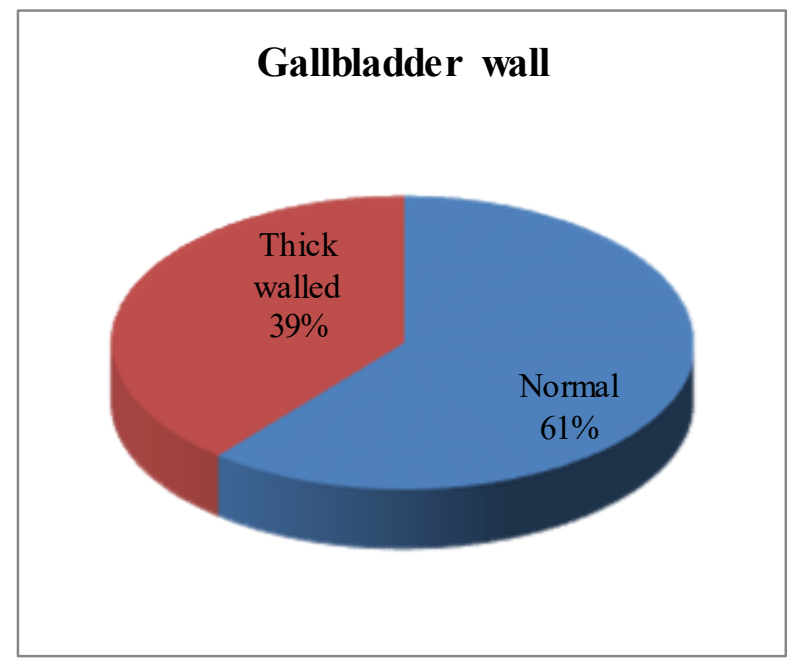

Diagram (2): Gallbladder wall distribution

Table (1): ASA distribution of the study group

\begin{tabular}{|l|l|l|}
\hline ASA & No. & $\%$ \\
\hline I & 68 & 68 \\
\hline II & 32 & 32 \\
\hline III+ & $\mathbf{0}$ & $\mathbf{0}$ \\
\hline Total & $\mathbf{1 0 0}$ & 100 \\
\hline
\end{tabular}

ASA: American Society of Anesthesiologists physical status classification system

Table (2): ERCP distribution of the study group

\begin{tabular}{|l|l|l|}
\hline ERCP & No. & $\%$ \\
\hline NO & 95 & 95 \\
\hline PRE- OP ERCP & 5 & 5 \\
\hline Total & $\mathbf{1 0 0}$ & $\mathbf{1 0 0}$ \\
\hline
\end{tabular}

\section{ERCP: Endoscopic retrograde cholangiopancreatography:}

Diagram (3) showed highly statistically significant relation between level of CLOC risk scoring system and age (years). $(p<0.001)$; Diagram (4) shows statistically significant increase in difficulty in male compared to female. $(\mathrm{p}<0.019)$; Table (3) showed statistically significant relation between levels of CLOC risk scoring system and indication $(p=0.002)$. Table (4) showed statistically significant relation between levels of CLOC risk scoring system and ASA ( $p=0.002)$. Table (5) showed highly statistically significant relation between levels of CLOC risk scoring system and ASA $(p<0.001)$. 


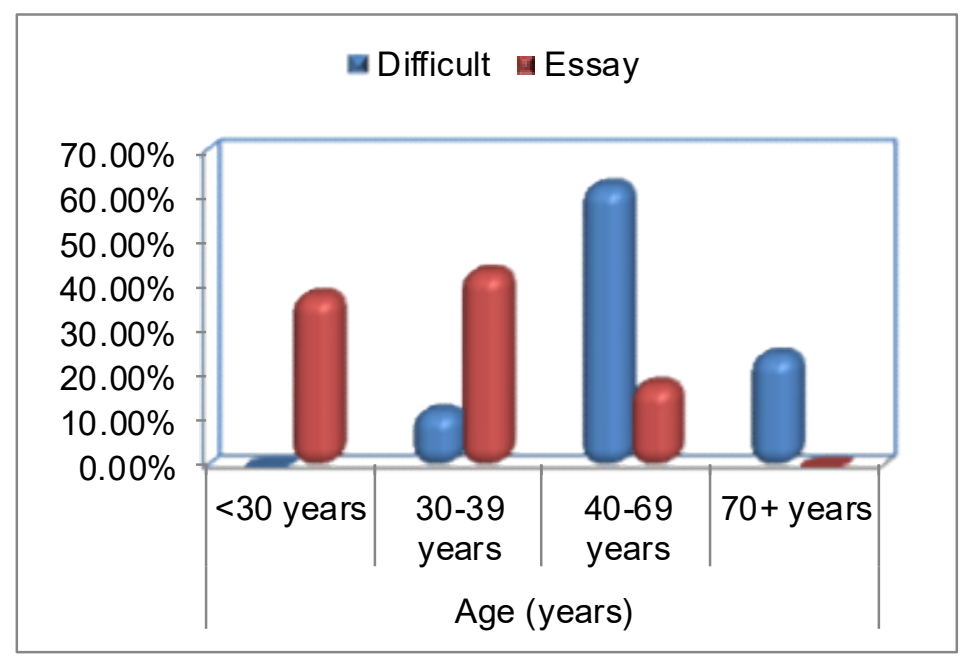

Diagram (3): Relation between levels of CLOC risk scoring system according to age (years).

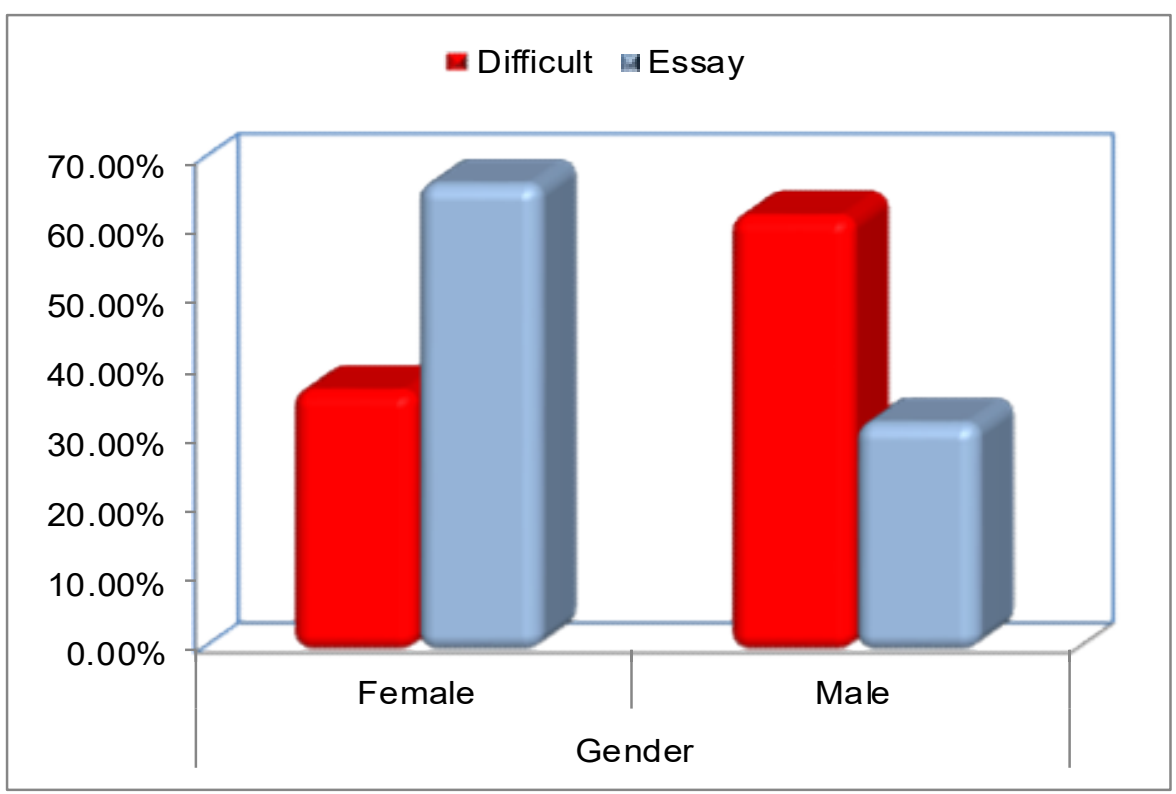

Diagram (4): Relation between levels of CLOC risk scoring system and gender.

Table (3): Relation between levels of CLOC risk scoring system and indication

\begin{tabular}{|l|c|c|c|c|l|l|}
\hline \multirow{2}{*}{ Indication } & \multicolumn{3}{|c|}{ Level of CLOC risk scoring system } & \multirow{2}{*}{ x2 } & \multirow{2}{*}{ p-value } \\
\cline { 2 - 5 } & \multicolumn{2}{|c|}{ Difficult } & & \\
\cline { 2 - 5 } & No. & $\%$ & No. & $\%$ & & \\
\hline Colic/ Pancreatitis & 0 & $0.0 \%$ & 24 & $31.6 \%$ & \multirow{2}{*}{9.972} & \multirow{2}{*}{$0.002^{*}$} \\
\hline Cholecystitis & 24 & $100.0 \%$ & 52 & $68.4 \%$ & & \\
\hline Total & 24 & $100.0 \%$ & 76 & $100.0 \%$ & & \\
\hline
\end{tabular}

x2: Chi-square test; *p-value $<0.05 \mathrm{~S}$; 
Table (4): Relation between levels of CLOC risk scoring system and ASA

\begin{tabular}{|l|l|l|l|l|l|l|}
\hline \multirow{4}{*}{ ASA } & \multicolumn{3}{|l|}{ Level of CLOC risk scoring system } & \multirow{2}{*}{ x2 } & \multirow{2}{*}{-value } \\
\cline { 2 - 5 } & Difficult & \multicolumn{2}{|l|}{ Essay } & \\
\cline { 2 - 5 } & No. & $\%$ & No. & $\%$ & \\
\hline I & 10 & $41.7 \%$ & 58 & $76.3 \%$ & & \multirow{2}{*}{0.064} \\
\hline II & 14 & $58.3 \%$ & 18 & $23.7 \%$ & & \\
\hline Total & 24 & $100.0 \%$ & 76 & $100.0 \%$ & \\
\hline
\end{tabular}

x2: Chi-square test; ${ }^{*}$ p-value $<0.05 \mathrm{~S}$;

Table (5): Relation between levels of CLOC risk scoring system and gallbladder wall thickness

\begin{tabular}{|l|c|c|c|c|c|l|}
\hline \multirow{2}{*}{ Gallbladder wall } & \multicolumn{3}{|c|}{ Level of CLOC risk scoring system } & \multirow{2}{*}{ x2 } & \multirow{2}{*}{ p-value } \\
\cline { 2 - 5 } & \multicolumn{2}{|c|}{ Difficult } & \multicolumn{2}{|c|}{ Essay } & \\
\cline { 2 - 5 } & No. & $\%$ & No. & $\%$ & & \\
\hline Normal & 8 & $33.3 \%$ & 53 & $69.7 \%$ & \multirow{2}{*}{10.161} & $<0.001^{* *}$ \\
\hline Thick walled & 16 & $66.7 \%$ & 23 & $30.3 \%$ & & \\
\hline Total & 24 & $100.0 \%$ & 76 & $100.0 \%$ & & \\
\hline
\end{tabular}

x2: Chi-square test; ${ }^{* *}$ p-value $<0.001 \mathrm{HS}$

Table (6) showed statistically significant relation between levels of CLOC risk scoring system and preoperative ERCP patients. $(\mathrm{p}=0.003)$. Table (7) showed statistically significant relation between observations and level of CLOC risk scoring. There was actual conversion according to groups with 'high risk scoring $>7$ and conversions in the' low risk $>6$ easy' group below. $(\mathrm{p}=0.042)$.

Table (6): Relation between levels of CLOC risk scoring system and preoperative ERCP patients

\begin{tabular}{|l|l|l|l|l|l|l|}
\hline \multirow{2}{*}{ ERCP } & \multicolumn{9}{|l|}{ Level of CLOC risk scoring system } & \multirow{2}{*}{ x2 } & \multirow{2}{*}{-value } \\
\cline { 2 - 6 } & Difficult & Essay & & \\
\cline { 2 - 6 } & No. & $\%$ & No. & $\%$ & & \\
\hline No & 20 & $83.3 \%$ & 75 & $98.7 \%$ & \multirow{2}{*}{9.049} & $0.003 *$ \\
\hline Yes & 4 & $16.7 \%$ & 1 & $1.3 \%$ & & \\
\hline Total & 24 & $100.0 \%$ & 76 & $100.0 \%$ & & \\
\hline
\end{tabular}

x2: Chi-square test; *p-value $<0.05 \mathrm{~S}$;

Table (7): Relation between researcher observation and level of CLOC risk scoring

\begin{tabular}{|c|c|c|c|c|c|c|c|c|}
\hline \multirow{3}{*}{$\begin{array}{l}\text { Level of CLOC } \\
\text { risk scoring system }\end{array}$} & \multicolumn{6}{|c|}{ Conversions } & \multirow[t]{3}{*}{$\mathrm{r}$} & \multirow[t]{3}{*}{$\mathrm{p}$-value } \\
\hline & \multicolumn{2}{|c|}{ Open } & \multicolumn{2}{|c|}{ Laparoscopy } & \multicolumn{2}{|c|}{ Total } & & \\
\hline & No. & $\%$ & No. & $\%$ & No. & $\%$ & & \\
\hline Difficult & 3 & $60 \%$ & 21 & $22.1 \%$ & 24 & $24 \%$ & 0.396 & $0.042 *$ \\
\hline Easy & 2 & $40 \%$ & 74 & $77.9 \%$ & 76 & $76 \%$ & & \\
\hline Total & 5 & $100 \%$ & 95 & $100 \%$ & 100 & $100 \%$ & & \\
\hline
\end{tabular}

r: Spearman's Correlation Coefficient; **p-value $<0.001$ HS

Diagram (5) showed highly statistically significant increase of mean in difficult group compared to essay group according to duration of surgery. $(\mathrm{p}<0.001)$; Diagram (6) show highly statistically significant increase of mean in difficult group compared to essay group according to POD (days). $(\mathrm{p}<0.001)$ 


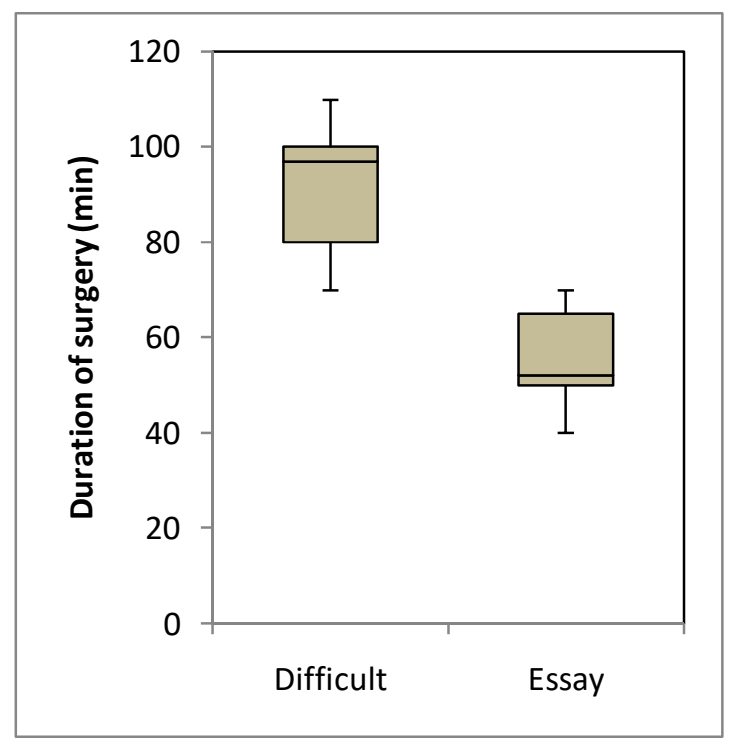

Diagram (5): Box plot between easy \& difficult according to surgery duration

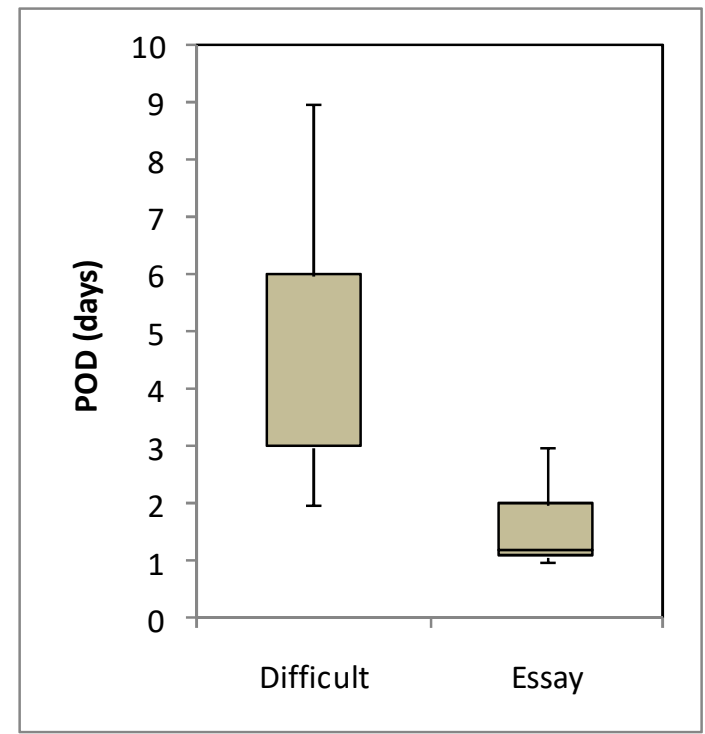

Diagram (6): Box plot between easy \& difficult According to POD

Diagram (7): Receiver-operating difficult surgery using the CLOC risk characteristic (ROC) curve for prediction of scoring system.

\begin{tabular}{|l|l|l|l|l|}
\hline Sensitivity & Specificity & $P P V$ & $N P V$ & $A U C$ \\
\hline $92.0 \%$ & $98.7 \%$ & $95.8 \%$ & $97.4 \%$ & 0.970 \\
\hline
\end{tabular}

Table (8) shows highly statistically significant higher complication in difficult group compared to essay group $(\mathrm{p}<0.001)$; Table (9) shows that age, gender, indication,
ASA, gallbladder wall and Pre-Operative ERCP have a significant effect on the difficulty. 


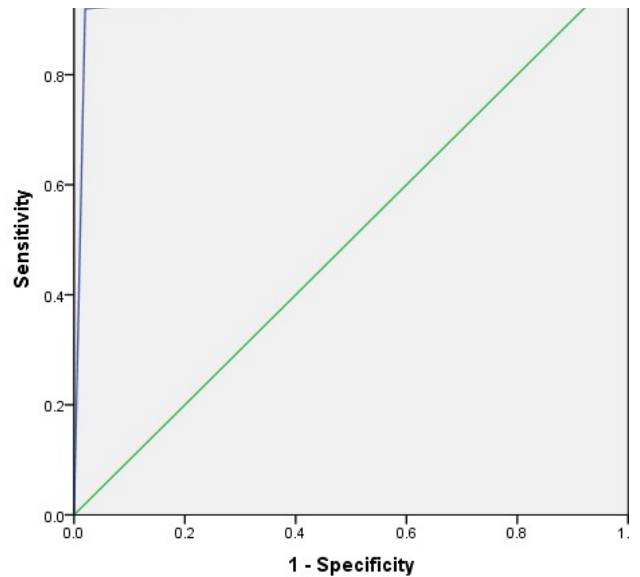

Table (8): Comparison between difficult and essay according to complications $(n=100)$.

\begin{tabular}{|c|c|c|c|c|c|c|}
\hline \multirow[t]{3}{*}{ Complications } & \multicolumn{4}{|c|}{ Level of CLOC risk scoring system } & \multirow[t]{3}{*}{$\mathrm{x} 2$} & \multirow[t]{3}{*}{ p-value } \\
\hline & \multicolumn{2}{|c|}{ Difficult } & \multicolumn{2}{|c|}{ Essay } & & \\
\hline & No. & $\%$ & No. & $\%$ & & \\
\hline No & 6 & $25.0 \%$ & 68 & $89.5 \%$ & \multirow[t]{11}{*}{43.401} & \multirow[t]{11}{*}{$<0.001 * *$} \\
\hline Yes & 18 & $75.0 \%$ & 8 & $10.5 \%$ & & \\
\hline Gallbladder rupture & 9 & $37.5 \%$ & 3 & $2.6 \%$ & & \\
\hline$D V T$ & 3 & $12.5 \%$ & 1 & $1.3 \%$ & & \\
\hline Cystic duct avulsion & 1 & $4.2 \%$ & 0 & $0.0 \%$ & & \\
\hline CBD injury & 2 & $8.3 \%$ & 0 & $0.0 \%$ & & \\
\hline Postoperative ERCP & 2 & $8.3 \%$ & 0 & $1.3 \%$ & & \\
\hline Intra-operative heamorrage & 5 & $5.0 \%$ & 2 & $2.6 \%$ & & \\
\hline Biloma & 1 & $4.2 \%$ & 0 & $0.0 \%$ & & \\
\hline post cholecystectomy syndrome & 0 & $0.0 \%$ & 2 & $2.6 \%$ & & \\
\hline Total & 24 & $100.0 \%$ & 76 & $100.0 \%$ & & \\
\hline
\end{tabular}

$x^{2}$-Chi-square test; ${ }^{* *}$ p-value $<0.001 H S$ (DVT): deep vein thrombosis 
Table (9): Multivariable binary logistic regression model analysis using the difficulty vs. patients as the dependent variable and the age, gender, indication, ASA, Gallbladder wall and ERCP as the independent variable in patients group

\begin{tabular}{|c|c|c|c|c|c|}
\hline \multirow{2}{*}{ Parameters } & \multirow{2}{*}{ Co-efficient } & \multirow{2}{*}{ Odds ratio } & \multicolumn{2}{|c|}{ 95\% C.I. } & \multirow{2}{*}{ p-value } \\
\hline & & & Lower & Upper & \\
\hline \multicolumn{6}{|l|}{ Age (years) } \\
\hline$<30$ years & -- & -- & -- & -- & -- \\
\hline $30-39$ years & 1.936 & 6.933 & 1.173 & 22.981 & $0.033^{*}$ \\
\hline $40-69$ years & 2.686 & 4.667 & 2.178 & 18.777 & $0.006^{*}$ \\
\hline $70+$ years & 1.442 & 3.556 & 0.289 & 12.379 & $0.017 *$ \\
\hline \multicolumn{6}{|l|}{ Gender } \\
\hline Female & -- & -- & -- & -- & -- \\
\hline Male & -1.539 & 0.983 & 0.231 & 3.473 & $0.028 *$ \\
\hline \multicolumn{6}{|l|}{ Indication } \\
\hline Colic/ Pancreatitis & -- & -- & -- & -- & -- \\
\hline Cholec-ystitis & -0.418 & 0.658 & 0.365 & 1.186 & $0.016^{*}$ \\
\hline \multicolumn{6}{|l|}{ ASA } \\
\hline I & -- & -- & -- & -- & -- \\
\hline II & -0.753 & 0.471 & 0.290 & 0.764 & $0.011 *$ \\
\hline \multicolumn{6}{|l|}{ Gallbladder wall } \\
\hline Normal & -- & -- & -- & -- & -- \\
\hline Thick walled & -1.528 & 0.217 & 0.081 & 0.578 & $0.006 *$ \\
\hline \multicolumn{6}{|l|}{ ERCP CBD diameter } \\
\hline Normal & -- & -- & -- & -- & -- \\
\hline Dilated & -2.708 & 0.067 & 0.007 & 0.630 & $0.018^{*}$ \\
\hline
\end{tabular}

\section{DISCUSSION:}

In the present study, cholecystitis was the most reported indication. This agreed with $^{6^{8_{7}}}$ and didn't match with ${ }^{8}$. The majority of our patients recorded ASA. That had been detected by ${ }^{9}$ and while ${ }^{10}$ showed the opposite view. The majority of our patients had normal gall bladder wall; this disagrees with $^{10}$; where $(46 / 50)$ of patients had thick wall.

The results showed that $(95 \%)$ of the study cases had normal CBD diameter while preoperative ERCP was done in $(5 \%)$. Recently, in ${ }^{11}$, ERCP was done in $(8 \%)$ cases. The majority of the study group recorded easy total score $(76 \%)$; similar findings were obtained by ${ }^{12} ;{ }^{13} ;{ }^{14}$. Open surgery was conducted in $(5 \%)$ of the study cases; this agrees with ${ }^{9}$.

The current studied showed a statistically significant relation between
CLOC risk scoring system levels and indication. $\quad(p=0.002)$; ASA $\quad(p=0.002)$; preoperative ERCP patients. $(\mathrm{p}=0.003)$ and highly statistically significant relation with gallbladder wall thickness. $(\mathrm{p}<0.001)$.

Increased risk of conversion with statistical significance was found for acute cholecystitis in ${ }^{15}$ study and ${ }^{16}$ study confirmed that ASA score; pre-operative ERCP; a thick-walled gallbladder and a dilated CBD were significant predictors of difficult surgery

We could demonstrate statistically significant relation between observations and level of CLOC risk scoring. There was actual conversion according to groups with 'high risk scoring $>7$ and conversions in the' low risk $>6$ easy' group below. $(p=0.042)$

In the validation set $\mathrm{in}^{3}$, the risk of conversion to open for low $(\mathrm{CLOC} \leq 6)$ and high risk $(\mathrm{CLOC}>6)$ patients was $1.2 \%$ and $7.1 \%$, respectively. Hence, patients identified as high risk had a near six-fold 
higher rate of conversion than low risk patients. The CLOC score might help to identify high risk patients, in whom an early decision to convert would avoid a lengthy laparoscopic procedure.

In the present work, there was highly statistically significant increase of mean in difficult group compared to essay group according to duration of surgery, $(p<0.001)$ and according to POD (days), $(\mathrm{p}<0.001)$

According to ${ }^{17}$ conversion to open surgery was significantly associated with longer operating time ${ }^{18}$. Results showed that in conversion group there was increase in duration of total hospital stay by more than 24 hours in about $(90.1 \%)$ of patients.

The results of the current study had observed highly statistically significant higher complication in difficult group compared to essay group, $(p<0.001)$. The rate of complications was $(75 \%$ versus $10.5 \%)$

Receiver operating characteristics (ROC) curve was used to define the sensitivity of $92 \%$ specificity of $98.7 \%$ positive predictive value of $95.8 \%$, negative predictive value of $97.4 \%$ with diagnostic AUC of $0.970 \%$.

As for predicting the risk of conversion from laparoscopic to open surgery in ${ }^{19}$, the scoring system had $73 \%$ sensitivity and $87 \%$ specificity with $\mathrm{P}=0.001$ making it a highly significant association. The preoperative prediction scoring system used in ${ }^{12}$ study for prediction of difficult laparoscopic cholecystectomy with sensitivity and specificity of their scoring system for prediction of easy or difficult laparoscopic cholecystectomy were $93.75 \%$ and $52.94 \%$ respectively.

The current study results showed that age, gender, indication, ASA, gallbladder wall and Pre-Operative ERCP have a significant effect on the difficulty.
Similar findings were obtained in different investigations; ${ }^{20}$ study found that advanced age, presentation with acute cholecystitis, and choledocholithiasis affected difficulty. LC was technically difficult when performed later than $96 \mathrm{~h}$ after symptom onset in patients with grade II AC. Moreover, male sex also affects difficulty in ${ }^{21}$ study. Previous history of hospitalization for acute cholecystitis and wall thickness of GB (in both univariate and multivariate analysis), along with age, sex, palpable GB, and impacted stone (in univariate analysis) were found to be statistically significant to predict difficult LC in ${ }^{22} \& 23$ study conducted in Aswan University Hospital.

Conclusion: Parameters like older age, male gender, cholecystitis, ASA, thick wall GB, preoperative ERCP were predictors for difficult LC. These were risk factors and predictors for conversion to open cholecystectomy. CLOC" risk score may be the most helpful tool in stratifying risks

Recommendations:

Proper preparation of patients preoperatively is needed. Predictive factors could be used to plan the intervention. More attention should be given to demographic data, history and clinical examination to predict the difficult LC. Adequate training and experience of the surgeon, proper execution of appropriate technique and accurate identification of the anatomy are essential guidelines for prevention of complications.

\section{REFERENCES}

1. Goonawardena J, Gunnarsson R, de Costa A. Predicting conversion from laparoscopic to open cholecystectomy presented as a probability nomogram based on preoperative patient risk factors. Am J Surg. 2015; 210:492-500.

2. Sutcliffe RP, Hollyman M, Hodson J, et al. Preoperative risk factors for conversion from laparoscopic to open 
cholecystectomy: a validated risk score derived from a prospective U.K. database of 8820 patients. HPB (Oxford). 2016; 18(11):922-928.

3. Osman TA, Embaby MM, Mohamed RS. Difficult Laparoscopic Cholecystectomy: Could it be Anticipated Preoperatively? A Prospective Study of the Predicting Surrogates. MJMR, Vol. 29, No. 2, 2018, pages (54-62).

4. Hu ASY, Menon R, Gunnarsson R, de Costa A. Risk factors for conversion of laparoscopic cholecystectomy to open surgery - A systematic literature review of 30 studies. Am J Surg. 2017 Nov; 214(5):920-930.

5. Nassar AHM, Ashkar KA, Mohamed AY, Hafiz AA. Is laparoscopic cholecystectomy possible without video technology? Minim Invasive Ther Allied Technol. 1995; 4:63-65.

6. Ghadhban BR. Assessment of the difficulties in laparoscopic cholecystectomy among patients at Baghdad province. Ann Med Surg (Lond). 2019;41:16-19.

7. Musbahi A, Abdulhannan P, Bhatti J, Dhar R, Rao M, Gopinath B. Outcomes and risk factors of cholecystectomy in high risk patients: A case series. Ann Med Surg (Lond). 2020; 50:35-40.

8. Genc V, Sulaimanov M, Cipe G, et al. What necessitates the conversion to open cholecystectomy? A retrospective analysis of 5164 consecutive laparoscopic operations. Clinics (Sao Paulo). 2011; 66(3):417-420.

9. Ekici U, Y1lmaz S, Tatlı F. Comparative Analysis of Laparoscopic Cholecystectomy Performed in the Elderly and Younger Patients: Should We Abstain from Laparoscopic Cholecystectomy in the Elderly?. Cureus. 2018; 10(6):e2888.

10. Morimoto $\mathrm{Y}$, Mizuno $\mathrm{H}$, Akamaru $\mathrm{Y}$, Yasumasa $\mathrm{K}$, Noro $\mathrm{H}$, Kono $\mathrm{E}$, et al. Predicting prolonged hospital stay after laparoscopic cholecystectomy. Asian J Endosc Surg 2015; 8:289-295.
11. Yassein T, Iyoab I, Sallam A, Gomaa M, Sadek A, Osman M, Ibrahium T, Aziz AM. Predicting the risk factors of difficult laparoscopic cholecystectomy step by step. Egypt J Surg 2020; 39:515-22

12. Siddiqui MA, Rizvi SAA, Sartaj S, Ahmad I, Rizvi SWA. A Standardized Ultrasound Scoring System for Preoperative Prediction of Difficult Laparoscopic Cholecystectomy. J Med Ultrasound. 2017; 25(4):227-231.

13. Shaban H, Alsehily A, Elhadary MK, Elkerkary MA. Evaluation the Effectiveness of Pre-Operative Prediction Scoring System for Difficult Laparoscopic Cholecystectomy. J Surg 5. 2020; 1297 . DOI: $10.29011 / 2575$ 9760.001297

14. Jalil T, Adibi A, Mahmoudieh M, Keleidari B. Could preoperative sonographic criteria predict the difficulty of laparoscopic cholecystectomy?. J Res Med Sci. 2020; 25:57.

15. Liu CL, Fan ST, Lai EC, Lo CM, Chu KM. Factors affecting conversion of laparoscopic cholecystectomy to open surgery. Arch Surg. 1996 Jan; 131(1):98101.

16. Nassar AHM, Hodson J, Ng HJ, Vohra RS, Katbeh T, Zino S, Griffiths EA; CholeS Study Group, West Midlands Research Collaborative. Predicting the difficult laparoscopic cholecystectomy: development and validation of a preoperative risk score using an objective operative difficulty grading system. Surg Endosc. 2020 Oct; 34(10):4549-4561.

17. Kama NA, Kologlu M, Doganay M, Reis E, Atli M, Dolapci M. A risk score for conversion from laparoscopic to open cholecystectomy.2001; Am J Surg 181(6):520-525.

18. Hussain GM, Bhat SA, Khan T, Want MA, Mailk AA, et al. Conversion of Laparoscopic Cholecystectomy to Open Cholecystectomy: An Analysis in a High Risk Group of Patients. J Univer Surg. 2017; Vol. 5 No. 3:19 doi: $10.21767 / 2254-6758.100087$ 


\section{Halim El Thany Nader Halim Grace, et al.,}

19. Abdel Dayem M \& Osgood L, Escofet X \& Farag M. A New Preoperative Scoring System to Predict Difficulty of Laparoscopic Cholecystectomy and Risk of Conversion to Open Surgery. Indian Journal of Surgery (August 2020); 82(4):501-506.

20. Chandio A, Timmons S, Majeed A, Twomey A, Aftab F. Factors influencing the successful completion of laparoscopic cholecystectomy. JSLS. 2009; 13(4):581586.

21. Inoue $\mathrm{K}$, Ueno $\mathrm{T}$, Douchi $\mathrm{D}$, et al. Risk factors for difficulty of laparoscopic cholecystectomy in grade II acute cholecystitis according to the Tokyo guidelines 2013. BMC Surg 2017; 17:114.

22. Chand P, Singh R, Singh B, Singla RL, Yadav M. Preoperative Ultrasonography as a Predictor of Difficult Laparoscopic Cholecystectomy that Requires Conversion to Open Procedure. Niger J Surg. 2015; 21(2):102-105.

23. Saleem AEA and Abdallah HA. Evaluation of preoperative predictive factors for difficult laparoscopic cholecystectomy in comparison with intraoperative parameters. Egypt J Surg 2018; 37:504-11.

\section{دراسة مستقبلية لوقوع تحويل استئصال المرارة بالمنظار لفتح استئصال المرارة في مائة مريض}

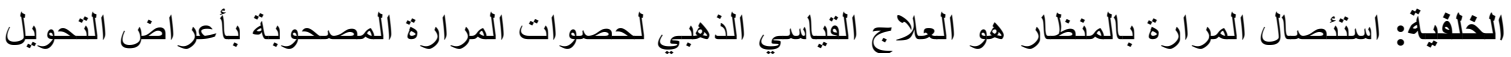
إلى إجر اء مفتوح ضروري في 0ـ • (٪ من المرضى.

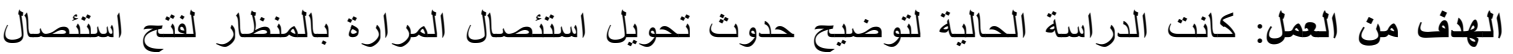

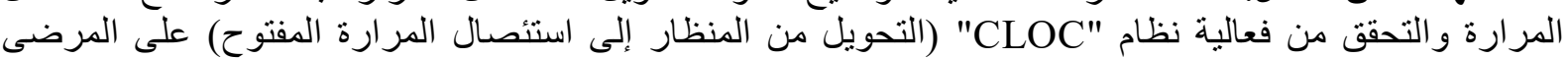
المشمولين بالدر اسة.

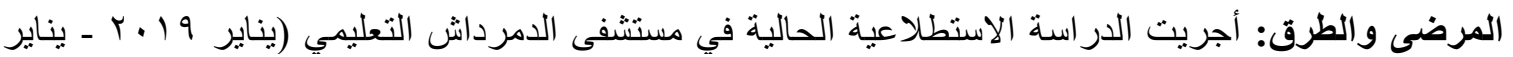

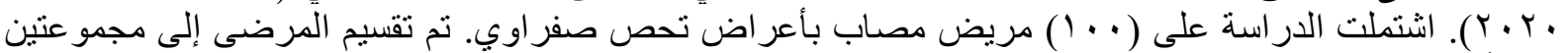

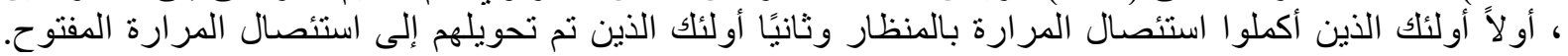

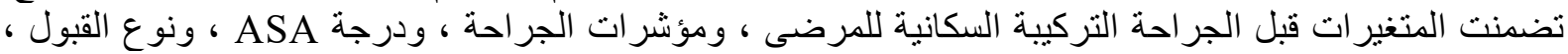

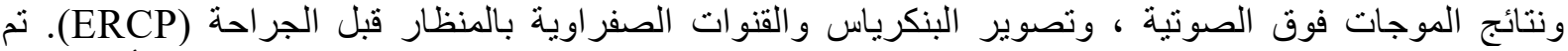

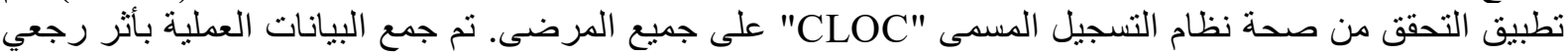

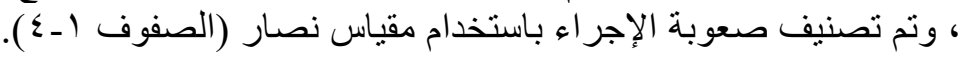

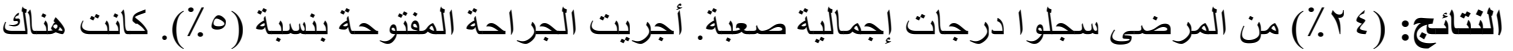
علاقة ذات دلالة إحصائية بين مستوى تسجيل مخاطر CLOC و العمر (PSA

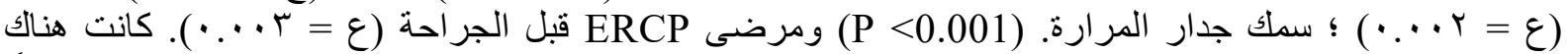

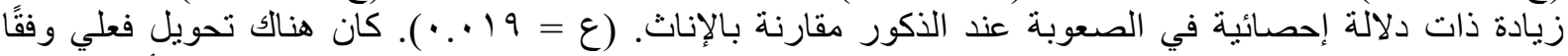

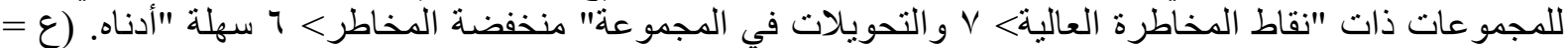

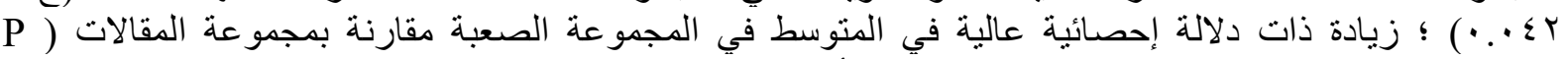

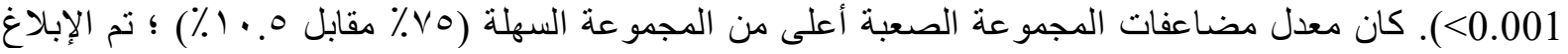

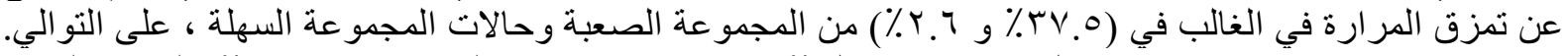
كانت حساسية منحنى خصائص تشغيل جهاز الاستقبال \% و الإشارة و ASA وجدار المرارة و ERCP قبل الجر احة لها تأثير كبير على الصعوبة.

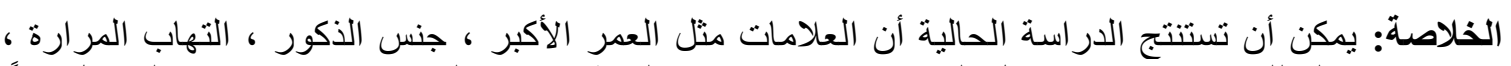

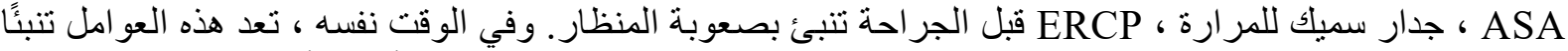
بالتحويل إلى استئصال المرارة المفتوح. قد تكون درجة مخاطر CLOC "هي الأداة الأكثر فائدة في تصنيف المخاطر إلى طبقات. 